\title{
Discurso, Memória, Alteridade: diálogos e confrontos identitários contemporâneos
}

\section{Discourse, Memory, Otherness: contemporary dialogues and identity confrontations}

\author{
Maria da Glória Corrêa di Fanti \\ Pedro Theobald ${ }^{2}$ \\ Ana Maria Lisboa de Mello ${ }^{3}$ \\ 1,2 Pontifícia Universidade Católica do Rio Grande do Sul, Escola de Humanidades, Programa de Pós-Graduação em Letras. \\ ${ }^{3}$ Universidade Federal do Rio de Janeiro, Faculdade de Letras, Programa de Pós-Graduação em Letras Neolatinas.
Rio de Janeiro, RJ, Brasil.
}

1 Professora-pesquisadora do Programa de PósGraduaçáo em Letras da Escola de Humanidades da Pontificia Universidade Catolica do Rio Grande CNPq. (1) https: $/$ orid org/0000-0002-5399-5377 E-mail: gloria.difanti@pucrs.br

Professor-pesquisador do Programa de PósGraduação em Letras da Escola de Humanidades da Pontifícia Universidade Católica do Rio Grande do Sul.

(i) https://orcid.org/0000-0002-6920-2669

E-mail: perth@pucrs.b

Professora do Programa de Pós-Graduação em de Jneiro Bolsista de Produtividade em Pesqus CNPq $1 C$

E-mail: /orid.org/0000-0002-0651-1974

E-mail: ana.lisboa11@gmail.com
Rre rês eixos centrais - discurso, memória, alteridade - conduzem as reflexões deste número da Letrônica, comemorativo aos 10 anos da Revista. Por que essa escolha temática? Que abordagens teóricas, dentre diferentes possibilidades, suscitam a abertura deste número especial?

A escolha da tríade discurso, memória, alteridade deve-se à abrangência da Revista, que contempla pesquisas desenvolvidas no campo dos estudos da linguística e da literatura e suas diferentes interfaces. Essas áreas, embora com particularidades próprias, têm em comum a linguagem. E é na linguagem, vista por uma perspectiva discursiva, que se considera a memória e a alteridade como constitutivas da produção de sentidos. 0 discurso e/ou a memória e/ou a alteridade têm suscitado diferentes pesquisas na contemporaneidade, como é o caso da amostragem publicada neste dossiê. Passemos a algumas reflexões que têm nos provocado o diálogo.

Dentre as possibilidades de abordagens teóricas que tratam do discurso, a desenvolvida pelo Círculo de Bakhtin apresenta uma perspectiva cara a este número temático, especialmente por contemplar os estudos da linguística e da literatura como complementares. ${ }^{1}$ Essa percepção pode ser observada, dentre outras obras, em $O$ texto na linguística, na

1 O Círculo de Bakhtin é formado por um grupo de estudiosos, cujos principais integrantes da área da linguagem são M. Bakhtin, V. N. Volóchinov e P.N. Medvedev, que tinham interesses filosóficos comuns e se reuniam para debater suas ideias, principalmente entre 1919 e 1929, na Rússia (CLARK; HOLQUIST, 1998; MORSON EMERSON, 2008; FARACO, 2009). 
filologia e em outras ciências humanas: um experimento de análise filosófica, quando Bakhtin (2016a, p. 71) circunscreve sua abordagem analítica como "filosófica". ${ }^{2}$ O pensador russo começa sua reflexão apresentando três considerações designadas como de índole negativa - "não é uma análise linguística, nem filológica, nem de investigação literária ou qualquer outra análise (investigação) especial” -, para então delimitar sua perspectiva via considerações positivas: "nossa pesquisa transcorre nos campos limítrofes, isto é, nas fronteiras de todas as referidas disciplinas, em seus cruzamentos e junções".

É nessa perspectiva que, em Problemas da poética de Dostoiévski, Bakhtin (2010, p. 207) propõe a observação do discurso, considerado como "a língua em sua integridade concreta e viva, e não a língua como objeto específico da linguística”. Sua proposta, a metalinguística, volta-se para a vida do discurso, ultrapassando os limites da linguística. Seus seguidores, como Todorov (1981), Clark e Holquist (1998) e Morson e Emerson (2008), designam essa tendência como "translinguística", o que a distingue do conceito de metalinguística comumente difundido nos estudos da linguagem. A translinguística, como o próprio prefixo "trans" anuncia, não ignora as contribuições da linguística, mas propõe ir "além" da linguística do sistema, considerando a complementaridade entre ambas. Enquanto a translinguística [metalinguística] estuda as relações dialógicas, as relações de sentido no discurso, no enunciado concreto, a linguística estuda as relações lógicas, concreto-semânticas, que carecem de dialogicidade e posição de autoria no enunciado (BAKHTIN, 2010, p. 210). Para a translinguística, "todo enunciado tem uma espécie de autor, que no próprio enunciado escutamos como o seu criador", mesmo que não saibamos "nada sobre o autor real, como ele existe fora do enunciado". Sob esse ponto de vista, podemos dizer que a translinguística "preocupa-se em observar a vida da linguagem, sua dinamicidade e caráter de novidade, o acontecimento, que permite a circulação de posições avaliativas de sujeitos situados histórico-socialmente e a permanente renovação de sentidos" (DI FANTI, 2012, p. 310).

Em Teoria do romance I: A estilística, Bakhtin (2015, p. 21) propõe "a superação do divórcio entre o 'formalismo' abstrato e o igualmente abstrato 'ideologismo' no estudo do discurso literário". Sua perspectiva baseia-se na "estilística sociológica", que considera a indissociabilidade entre a forma e o conteúdo no discurso, visto como fenômeno social. Para o filósofo da linguagem, "o romance é um heterodiscurso social [uma diversidade de vozes] artisticamente organizado, às vezes uma diversidade de linguagens e uma dissonância individual" (p. 29). ${ }^{3}$ O heterodiscurso se introduz no romance de

Os grifos nas citações são do autor.

3 O "heterodiscurso", conforme nota do tradutor Paulo Bezerra, é entendido como uma diversidade de vozes. É uma nova tradução para a palavra russa raznorétchie veiculada no Brasil como "plurilinguismo" e "heteroglossia" (BAKHTIN, 2015, p. 29). 
variadas formas, via autor, narradores, heróis, leitores, além de gêneros intercalados e outras manifestações de linguagem, admitindo uma diversidade de vozes sociais dialogadas em diferentes graus, que não podem ser ignoradas.

Para o pensador russo, o autêntico meio de toda enunciação, na vida, na arte e em qualquer forma de materialização, é o "heterodiscurso dialogizado, anônimo e social como a língua, mas concreto, rico em conteúdo e acentuado como enunciação individual" (BAKHTIN, 2015, p. 42). Nesse meio, há forças centrípetas e forças centrífugas, indissociáveis. Enquanto as primeiras buscam um movimento de centralização verboideológica, as segundas operam um movimento de descentralização, caracterizando a dinamicidade do discurso, o diálogo entre vozes e a impossibilidade de limitação a uma única força, ainda que uma delas predomine em cada enunciado, dependendo do gênero do discurso a que responde.

Os gêneros, de acordo com Bakhtin (2016b), organizam o nosso discurso, ou seja, falamos por gêneros, tipos de enunciados com relativa estabilidade, criados pelas necessidades sociais das múltiplas e complexas atividades humanas. Os gêneros surgem, desenvolvem-se e transformam-se conforme a nossa sociedade também se desenvolve. É por gêneros que a comunicação discursiva se estabelece. Por isso, é possível identificarmos pelas primeiras palavras do discurso alheio o gênero, características como o projeto enunciativo do dizer, os interlocutores, o tema e a organização do discurso. Isso se deve ao repertório necessário de práticas discursivas socializadas. Nesse sentido, há diferentes graus de plasticidade nos gêneros do discurso, o que implica variadas possibilidades de interferência do sujeito do discurso. A acentuação valorativa, própria de todo enunciado, varia conforme as coerções do gênero e sua apropriação pelo sujeito do discurso. Por um lado, em uma notícia, por exemplo, o jornalista não pode manifestar abertamente seu ponto de vista sobre o fato relatado, ainda que faça escolhas, via palavras, manchete e organização do dizer, distinguindo uma notícia da outra. Se a expressividade do jornalista for marcada linguisticamente (uso de primeira pessoa, palavras avaliativas etc.), ou seja, se seu ponto de vista fizer parte do projeto enunciativo do enunciado criado, a notícia não será reconhecida como gênero notícia, que tem como propósito informar, mas sim como outro gênero, como aqueles vinculados ao humor que tem o propósito de criticar (a exemplo das "notícias" do site Sensacionalista). ${ }^{4}$ Por outro lado, em um conto, gênero ficcional, há uma grande liberdade para o contista manifestar sua expressividade e criatividade. Faz parte do projeto enunciativo do gênero conto essa permanente reformulação livre e criadora da narrativa.

Essas reflexões remetem à diferença entre o domínio dos gêneros do discurso e o domínio da língua. Não basta dominar uma língua para dominar os gêneros. Da mesma forma, o "domínio do discurso em diferentes campos da comunicação cultural", como saber ler um relatório e desenvolver uma discussão científica, não garante bom desempenho

${ }^{4}$ o Sensacionalista: um jornal isento de verdade, é um noticiário satírico eletrônico brasileiro. <https://www.sensacionalista.com.br/>. 
em uma conversa do cotidiano, por exemplo, que exige conhecimento das características dos seus próprios enunciados (BAKHTIN, 2016b, p. 41-42): "ao falante não são dadas apenas as formas da língua nacional (a composição vocabular e a estrutura gramatical) obrigatórias para ele, mas também as formas igualmente obrigatórias de enunciado, isto é, os gêneros do discurso: esses são tão indispensáveis para a compreensão mútua quanto as formas da língua". ${ }^{5}$ Os gêneros, completa o filósofo russo, "são bem mais mutáveis, flexíveis e plásticos", comparados às formas da língua, ainda que tenham "significado normativo, não são criados [pelo falante] mas dados a ele", fazem parte do repertório social de uma dada comunidade discursiva. No entanto, o falante tem um espaço de atuação que revela o estilo dialógico, a sua relação com outros enunciados que singulariza a constituição heterogênea do dizer.

Para Bakhtin (2016b, p. 57), "todo enunciado é repleto de variadas atitudes responsivas [rejeição, confirmação, acréscimo etc.] a outros enunciados de um dado campo da comunicação discursiva”. Sendo pleno de ecos e ressonâncias de outros discursos, o enunciado configura-se, ao mesmo tempo, como uma resposta a enunciados precedentes e como antecipação a enunciados futuros. Tal perspectiva remete à memória discursiva, a vida do enunciado e a relação com seus rastros, e à alteridade da linguagem, a constitutiva relação com o outro, outros discursos e outros sujeitos (passados, presentes e futuros). Essa concepção instaura a dialogicidade interna do discurso que "penetra toda a sua estrutura, todas as camadas dos seus sentidos e de sua expressão" (BAKHTIN, 2015, p. 52): "o discurso surge no diálogo como sua réplica viva, forma-se na interação dinâmica com o discurso do outro no objeto". Todo discurso concreto (enunciado), conforme Bakhtin (Ibid., p. 48), "encontra o objeto para o qual se volta sempre, por assim dizer, já difamado, contestado, avaliado, envolvido ou por uma fumaça que o obscurece ou, ao contrário, pela luz de discursos alheios já externados a seu respeito". Nesse cenário, o discurso "não pode deixar de tocar milhares de linhas dialógicas vivas envoltas pela consciência socioideológica no entorno de um dado objeto da enunciação, não pode deixar de ser participante ativo do diálogo social". Dentre as manifestações da dialogicidade, propriedade do discurso, a influência do interlocutor na construção do enunciado é de grande relevância, pois "todo discurso está voltado para uma resposta e não pode evitar $a$ influência profunda do discurso responsivo antecipável” (id., ibid., 2015, p. 52).

Nos estudos sobre polifonia e dialogismo voltados à obra de Dostoiévski, Bakhtin (2010, p. 72) examina a autoconsciência das personagens na ficção do escritor russo, mostrando que seus heróis não são agentes do autor, marionetes, considerando que a orientação dialógica do romance - quando "o autor não fala do herói mas com o herói" - é

5 Conforme Volóchinov (2017, p. 177), para o falante, "a forma linguística é importante não como um sinal constante e invariável, mas como um signo sempre mutável e flexível" nos diferentes contextos ideológicos. Nesse sentido, a palavra "é o indicador mais sensível das mudanças sociais", já que ela, como signo ideológico, "surge entre indivíduos socialmente organizados no processo de sua interação" (id., ibid., p. 106; 108). 
a forma de dar lugar à palavra do outro, focalizá-lo "como posição racional ou outro ponto de vista". E Bakhtin acrescenta: "a orientação dialógica coparticipante é a única que leva a sério a palavra do outro mas sem se fundir com ela, sem absorvê-la nem absorver seu valor, ou seja, conserva inteiramente a sua autonomia como palavra” (id., ibid.). Na criação de Dostoiévski, como sublinha Bakhtin, não há "discurso definitivo", determinante, nem há "uma imagem sólida do herói que responda à pergunta "quem é ele", mas cabem apenas as perguntas: "quem sou eu?" e "quem és tu?". Essas perguntas também têm lugar "no diálogo interior contínuo e inacabado", de modo que não há, na criação literária do autor russo, um "discurso sólido, morto, acabado, que já pronunciou a sua última palavra" (Cf. BAKHTIN, 2010, p. 291-292), mas um discurso plenissignificativo, de interação dialógica dos discursos.

Os estudos de Bakhtin sobre a questão do outro - das relações do eu com o outro - antecipam perspectivas atuais sobre a questão da alteridade, um dos conceitos mais discutidos pelas ciências humanas contemporâneas. Pierre Ouellet observa que a alteridade é um fato:

[...] a penetração e impregnação cada vez mais profundas e duráveis dos mundos dos outros no nosso próprio mundo, seja pelo viés das numerosas e diversificadas migrações que nós conhecemos, seja pela multiplicação de trocas de toda espécie que não cessaram de se intensificar (OUELLET, 2007, p. 8).

Além de ser um fato, Ouellet assinala que a alteridade impõe-se como um tema em representações imaginárias e memoriais de variadas práticas discursivas, decorrente da nova realidade histórica marcada pela interpenetração constante de mundos (id., ibid., p. 8).

A essas considerações, poderíamos acrescentar que o deslocamento de inúmeras populações em busca de refúgio, no decorrer do século XX até os dias atuais, tem sido uma das principais causas dessa interpenetração de mundos e valores e da consciência do outro, de hábitos de vida, de idiomas. As migrações para outros países exigem esforços de adaptação, de conquista de um espaço em lugares que, em um primeiro momento, se afiguram como estranhos em vários aspectos, sobretudo quando a cultura do imigrante e a sua língua materna mantêm pouquíssimas relações com as do país de acolhida. Em contrapartida, nesse espaço, em que o imigrante é o outro, "o estrangeiro, definido por sua dessemelhança", como observa Eric Landowski, há confrontos identitários e, para os nativos, a necessidade de conviver "na imediatidade do cotidiano com modos de vida vindos de outros lugares, e cada vez mais heteróclitos" (LANDOWSKI, 2012, p. 4).

Doravante, a alteridade não é apenas um fato e um tema, mas também e acima de tudo, impõe-se como uma nova sensibilidade e uma valorização do mundo, que, de acordo com Ouellet, apoia-se em uma "heterogeneidade irredutível do real", que exige que repensemos os princípios de unidade e identidade que até então lhe serviam de base (Cf. OUELLET, 2007, p. 9). 
Os deslocamentos espaciais em busca de refúgio ou novas oportunidades de vida dão origem a uma nova estética literária, escrita por imigrantes ou seus descendentes de segunda ou terceira geração, que podemos chamar de "escrita migrante", produzida por escritores cuja identidade incorpora à herança familiar as novas experiências culturais vividas no locus de acolhida. A identidade dos escritores é compósita, em movimento, carregada da herança dos antepassados, mesclada à cultura do país de destino, como é o caso dos brasileiros Milton Hatoum, Salim Miguel, Michel Laub, Tatiana Salem Levy, e dos canadenses Abla Farhoud, Naïm Kattan e Ying Chen, entre outros. Nesses, a escritura literária revela um processo narrativo em que o narrador busca unir o presente e o seu próprio passado às memórias e aos legados de seus antepassados, o que significa tentar reconstituir a própria história e a própria identidade, recordando o que foi recalcado por vezes experiências traumáticas da família, mas também preservando os hábitos, e até mesmo a língua materna, como se observa no título de um dos romances de Salim Miguel - Nur na escuridão - que mantém um hibridismo linguístico não apenas no título, uma vez que, ao longo do romance, surgem vocábulos árabes. Essa bagagem herdada se articula e convive com a cultura do país de chegada e com novos conhecimentos e desafios.

Nessa escrita "migrante", transnacional, em que o autor expressa o imbricamento de culturas em um determinado espaço-temporal, abrangido pelo texto ficcional, é marcante a função da memória no relato ou pós-memória, que "designaria a memória da geração seguinte àquela que sofreu ou protagonizou os acontecimentos", segundo Beatriz Sarlo, em sua discussão do conceito a partir das obras de James Young e Marianne Hirsch (SARLO, 2007, p. 91). Fundada na mobilidade subjetiva e intersubjetiva, o narrador apela para a presentificação do passado através da memória, desencadeando um contínuo exercício de alteração de si mesmo, que exige um refazer-se a cada instante, o que significa tentar reconstituir a própria história e a própria identidade, recordando o que foi recalcado, recuperando as experiências traumáticas da família e a cultura dos antepassados.

Para Jean-Yves e Marc Tadié, em Le sens de la mémoire, "cada percepção do mundo exterior desencadeia em nós uma impressão de intensidade variável, agradável ou desagradável, carregada, portanto, de afeto” (TADIÉ; TADIÉ, 1999, p. 117). Segundo os teóricos, "um acontecimento particularmente proeminente produz em consequência um engrama naquilo que está em volta e teria sido esquecido se não fosse isso, como a queda de uma bomba forma em volta do seu impacto um fosso maior do que ela própria (id., ibid., p. 118)". A emoção desempenha, portanto, um papel relevante no funcionamento da memória. Quando exploramos o passado, espontaneamente, são sempre as mesmas imagens ou cenas que reaparecem, e a maior parte dessas lembranças é constituída de experiências que tiveram uma carga emocional ou afetiva mais forte do que os demais acontecimentos da vida cotidiana.

Escritores contemporâneos têm produzido obras literárias em que o acionamento da memória pelo narrador, personagem ou eu-lírico, estilhaçada no fluxo do pensamento, associa-se à história, sobretudo à barbárie que marcou 
o século XX, com a Guerra Civil Espanhola, o genocídio dos judeus na Segunda Guerra, a repressão stalinista na União Soviética, a violência dos processos de descolonização na África, as ditaduras militares nas Américas. Esses acontecimentos históricos provocaram exílios inelutáveis, refúgios temporários ou diásporas de populações em busca de oportunidades de vida, com segurança e emprego, dando origem a escritas literárias e memorialísticas, que fixaram indelevelmente esses acontecimentos na memória coletiva.

Tratar de discurso, memória e alteridade, neste número especial, convoca ao diálogo duas importantes abordagens finais: a primeira refere-se à recuperação do percurso da criação da Revista Letrônica, sua história, atualizações e perspectivas; e a segunda, à apresentação dos trabalhos que compõem esta publicação. Passemos à primeira. Considerando o cenário da pósgraduação brasileira, em que o Programa de Pós-Graduação em Letras (PPGL/PUCRS), em 2008, estava se reestruturando para enfrentar desafios no contexto acadêmico e social contemporâneos, a Letrônica foi criada pela então coordenadora do PPGL/PUCRS, a professora Ana Maria Lisboa de Mello, que atuou como editora da Revista. Com o apoio de alunos de doutorado, que atuaram como editores-júnior, a Letrônica visava, em seu princípio, criar um espaço de divulgação dos trabalhos de mestrandos e doutorandos do Programa. O próprio nome da Revista, cuja memória é importante resgatar, foi dado a partir de sugestões de alunos, via votação. 0 nome Letrônica surgiu da ideia de unir as palavras Letras e eletrônica, num momento em que ainda não era uma exigência a publicação on-line das revisas acadêmicas.

Com a preocupação de qualificar a produção do Programa e estimular a publicação dos mestrandos e doutorandos em periódicos fora da PUCRS, a Revista, nos anos seguintes, passou por um constante processo de atualização, como a avaliação por pares tanto de pareceristas do conselho editorial como de pareceristas ad hoc de diferentes universidades. Quando, em 2012, assumem a editoria da Letrônica os professores Maria da Glória di Fanti, da área de linguística, e Biagio d'Angelo, da área de literatura, os objetivos foram modificados, e a Revista passou a incentivar a publicação de pesquisadores de diferentes regiões do Brasil e do exterior. A Letrônica manteve, porém, a característica de ser uma revista temática. Na sua primeira avaliação da CAPES, ainda no ano de 2012, a Letrônica foi avaliada com o Qualis B2.

Mantendo a qualidade já alcançada e buscando sempre uma maior adequação às exigências do cenário acadêmico brasileiro e internacional, a Revista passou por revisão do conselho editorial e das normas de publicação. Em sua nova avaliação pela CAPES, a Revista atingiu o Qualis B1, correspondente ao quadriênio de avaliação dos programas de pósgraduação, 2013 a 2016, vigente até o momento. Em 2014, assume a editoria da área de literatura o professor Pedro Theobald. Na busca constante pelo aperfeiçoamento do periódico, neste ano, em que completa 10 anos, a Revista, aliada às exigências da Scielo e com o apoio da EDIPUCRS, passou a ter periodicidade trimestral, sendo dois números temáticos de cada grande área de abrangência: linguística e literatura. 
Quanto à segunda abordagem trazida para diálogo, passemos a apresentar os trabalhos publicados neste número especial, comemorativo aos 10 anos da Letrônica.

A série de artigos com temas da Linguística desta edição abre com um texto de Juán Manuel López Muñoz, da Universidad de Cádiz, e de Rafael Batista Andrade, da Universidade Federal de Minas Gerais. 0 artigo traz uma análise da canção "Sou eu mesmo, o trocado - Non, je ne regrette rien", de Maria Bethânia, a partir da teoria da circulação discursiva e da contribuição de Maingueneau à análise do discurso. 0 estudo revela a eficácia dessas teorias para a recategorização de textos de gênero híbrido.

O segundo artigo, de Marcella Machado de Campos e de Maria Cecília Pérez de Souza e Silva, ambas da Pontifícia Universidade Católica de São Paulo, problematiza o assim-chamado "fenômeno da pós-verdade". Empregando o conceito de desmemória discursiva, de Paveau, as autoras analisam declarações de autoridades políticas norte-americanas. Observam que certas manobras enunciativas, como retificações e ressignificações, empregadas para gerar novos sentidos enquanto o discurso antigo é esquecido, tendem a tornar-se a norma na produção de verdades.

Em "A (in)visibilidade na atividade de revisão de textos acadêmicos: um outro na cadeia de sentidos", Vanessa Fonseca Barbosa e Maria da Glória Corrêa di Fanti, da Pontifícia Universidade Católica do Rio Grande do Sul, estudam algumas facetas da atividade do revisor de textos acadêmicos. A análise de enunciados com base na ergologia e na teoria bakhtiniana mostra que a atividade do revisor, aparentemente invisível, instaura na realidade um outro deveras importante na constituição de sentidos do texto final.

"Ainda (e sempre) Saussure: história, memória e discurso em três versões de um mesmo texto", de Amanda Eloina Scherer e de Maria Iraci Souza Costa, da Universidade Federal de Santa Maria, aproveita o ensejo do centenário da primeira edição do Cours de Linguistique Génerale (2016) para propor um estudo sobre a recepção dessa obra na Argentina, no Brasil e em Portugal. As diferenças na compreensão do todo e de conceitos específicos do texto do linguista francês ocorrem porque, como afirma Sériot, um dos referenciais do estudo, "Em ciências humanas, os movimentos de ideias entre os países não se fazem em perfeita sincronia”. Para entender tais movimentos, é preciso reconstituir o contexto do passado.

O artigo seguinte, de Kelli da Rosa Ribeiro, da Fundação Universidade Federal do Rio Grande, aborda as questões de apreensão, transmissão e orientação do discurso alheio. Para tanto, o conceito de bivocalidade, do Círculo de Bakhtin, é empregado no estudo da transmissão do discurso bíblico no programa televisivo Show da fé. As relações entre fé, mercado, publicidade e consumo ficam evidentes na pesquisa.

O artigo de Liz Feré, da Université Paris VIII, que se pode ler na sequência, aborda as relações de alteridade no cotidiano atual da sociedade brasileira. Fundamentado nas teorias do Círculo de Bakhtin e de Bourdieu, o artigo estuda, 
especificamente, o discurso que expressa as relações raciais, evidenciando a base teórica racista, a falta de consciência da discriminação e a negação da existência de atitudes racistas no Brasil. 0 estudo mostra como "a linguagem influencia as relações pessoais, especialmente como a palavra e suas valorações potencializam as tensões vividas entre grupos cada vez mais antagônicos".

O último trabalho de Linguística deste número especial traz um artigo das professoras Johanna Dagort Billig, Aline Aver Vanin e Gabriela Peretti Wagner, da Fundação Universidade Federal de Ciências da Saúde de Porto Alegre. Trata-se de uma revisão da literatura concernente à relação entre as metáforas conceptuais e as funções executivas. No estudo de sete artigos recentes acerca do tema, constatou-se a existência de uma relação entre "desempenho em termos de memória de trabalho e de controle inibitório e a compreensão e produção de metáforas".

A série de Literatura desta edição comemorativa de Letrônica se inicia com "Memory and the written testimony: the actresses of the public theatre in Calcutta in the 19th and 20th century". O artigo, de Sarvani Gooptu, da Universidade de Calcutá, apresenta os resultados de uma pesquisa a respeito das primeiras atrizes do teatro em língua bengali. Embora se soubesse que existiram, essas damas do teatro permaneceram por quase duzentos anos na obscuridade. 0 estudo de notícias esparsas, e principalmente de relatos autobiográficos, integra as artistas na realidade da pesquisa cultural contemporânea.

O título do artigo seguinte, "Em teu ventre: quando a ficção é mais verossímil", de Ana Cláudia Munari Domingos, da Universidade de Santa Cruz do Sul, faz referência a um romance do escritor português José Luís Peixoto. O romance traz uma versão ficcionalizada das aparições de Nossa Senhora em Fátima, Portugal, história aqui utilizada para tentar compreender a tensão entre os elementos referenciais factuais e a elaboração fictícia. Teoricamente, o estudo se vale de um significado de memória elaborado por Maurice Halbwachs.

Segue-se um artigo de Pedro Theobald, da Pontifícia Universidade Católica do Rio Grande do Sul, a respeito da primeira recepção crítica da História da literatura ocidental de Otto Maria Carpeaux. Lançada separadamente em oito volumes, entre 1959 e 1966, a obra tornou-se amplamente conhecida e elogiada, não só no meio universitário brasileiro. Cada um dos volumes teve no crítico Wilson Martins um leitor cuidadoso e criterioso, que leu todos eles, reconheceu suas qualidades e lhes apontou os defeitos de concepção historiográfica.

"Mãe, materno mar, de Boaventura Cardoso: uma viagem pela memória de Angola", de Luara Pinto Minuzzi, também da Pontifícia Universidade Católica do Rio Grande do Sul, estuda o romance do conhecido escritor angolano a partir das Teorias do Imaginário. No estudo, a viagem de trem, que faz parte da realidade narrativa, também representa, em nível metafórico, a busca pelo conhecimento da história e das tradições de Angola. 
O artigo seguinte é "Memória e amnésia sexista: repertórios de exclusão das escritoras oitocentistas", de Ana Faedrich, da Universidade do Estado do Rio de Janeiro. A autora observa mecanismos de exclusão, como a crítica desencorajadora às autoras mulheres, e a luta destas para sobreviverem no mercado intelectual e literário. Um exemplo paradigmático referido pelo artigo é o de Amélia de Oliveira, noiva de Olavo Bilac, escritora, desencorajada pelo próprio poeta, e que cedeu às insistências do noivo, parando de publicar.

Em “A memória na literatura da Segunda Guerra Mundial: narrações como testemunho histórico e invenção", Milena Hoffmann Kunrath, da Universidade Federal de Pelotas, focaliza principalmente obras produzidas por ex-soldados. 0 artigo "coteja as possibilidades da narração, que compreendem ao mesmo tempo uma parte de relato histórico, ficção e de reorganização, ora intencional, ora não, de [...] recordações [...] marcantes". O encontro da realidade imaginada com a verdade histórica gera tensões, aqui examinadas em exemplos selecionados.

"Memórias do futuro: alteridade do mundo e do sujeito na poesia de Cecília Meireles" é o título do artigo de Márcia Helena Saldanha Barbosa, da Universidade de Passo Fundo. Baseada em teses de Michel Collot, a professora estuda as relações entre a poesia e o sagrado na obra poética de Cecília Meireles. O texto mostra que "o sujeito lírico, ao perceber a alteridade do mundo, é levado ao encontro de sua própria alteridade, numa busca em que o futuro imaginado confunde-se com as memórias difusas da origem".

A série de Literatura se encerra com "A contrastive overlook at Asian literatures in the Americas: two examples", de José I. Suárez, da University of Northern Colorado. 0 artigo observa os modos de adaptação de asiáticos no Brasil e nos Estados Unidos e a visão do Outro nas obras Yawara! A travessia Nihondin-Brasil, do nipo-brasileiro Júlio Miyazawa, e Yellow on the outside, shame on the inside: Asian culture revealed, do sino-americano Anson Chi.

A edição especial contém ainda uma entrevista com Evelyn Ferstl, da Albert-Ludwigs-Universität Freiburg. Realizada por Bernardo Kolling Limberger, da Universidade Federal de Pelotas, e Augusto Buchweitz, da Pontifícia Universidade Católica do Rio Grande do Sul, a conversa intitula-se “Discourse processing: an interview with Professor Evelyn Ferstl”. As perguntas contemplam domínios de especialidade da entrevistada, como o processamento do discurso e os estudos de gênero.

Concluímos esta reflexão, registrando nossos agradecimentos a todos que colaboraram, de alguma forma, para o processo de qualificação da Letrônica ao longo dos seus 10 anos de existência: equipe responsável pelos periódicos da EDIPUCRS, editores, editores-júnior, organizadores de dossiês, membros do conselho editorial, consultores ad hoc e autores. Neste número comemorativo, agradecemos especialmente a colaboração de importantes pesquisadores que prestigiam nossa Revista com suas investigações. A partir desse "heterodiscurso dialogizado", em que diferentes vozes se tocam (criando efeitos variados) para tratar de temas relevantes da contemporaneidade, oferecemos, aos nossos leitores, 
esse diálogo aberto pelas reflexões desenvolvidas, marcadas pelo movimento próprio da inconclusividade, que, na relação entre discurso, memória e alteridade, suscita diferentes respostas e novas perguntas, afinadas com os desafios do fazer acadêmico.

\section{Referências}

BAKHTIN, M. Problemas da poética de Dostoiévski (1963). Trad. Paulo Bezerra. 5. ed. Rio de Janeiro: Forense, 2010.

BAKHTIN, M. Teoria do romance I: A estilística (1930-1936). Org. da edição russa de Serguei Botcharov e Vadim Kójinov. Tradução, prefácio, notas e glossário de Paulo Bezerra. São Paulo: Editora 34, 2015.

BAKHTIN, M. O texto na linguística, na filologia e em outras ciências humanas: um experimento de análise filosófica (1959-1961). In: Os gêneros do discurso. Trad. Paulo Bezerra. Rio de Janeiro: Editora 34, 2016a. p. 71-107.

BAKHTIN, M. Os gêneros do discurso (1952-1953). Trad. Paulo Bezerra. Notas da edição russa de Serguei Botcharov. Rio de Janeiro: Editora $34,2016 \mathrm{~b}$.

CLARK, K.; HOLQUIST, M. Mikhail Bakhtin (1984). Trad. J. Guinsburg. São Paulo: Perspectiva, 1998.

DI FANTI, M. G. C. Linguagem e trabalho: diálogo entre a translinguística e a ergologia. Desenredo, v. 8, p. 309-329, 2012.

FARACO, C. A. Linguagem \& diálogo: as ideias linguísticas do Círculo de Bakhtin. São Paulo: Parábola Editorial, 2009.

LANDOWSKI, E. Presenças do outro. São Paulo: Perspectiva, 2012. (Estudos, 183).

MORSON, G. S.; EMERSON, C. Mikhail Bakhtin: criação de uma prosaística. Trad. Antonio de Pádua Danesi. São Paulo: Editora da Universidade de São Paulo, 2008.

OUELLET, P. (Dir.) Le principe d'altérité. Introduction. In: OUELLET, Pierre; HAREL, Simon. Quel autre? l'altérité en question. Montréal: VLB Éditeur, 2007.

SARLO, B. Tempo passado: cultura da memória e guinada subjetiva. São Paulo: Via das Letras; Belo Horizonte: Ed. UFMG, 2007.

TADIÉ, J-Y; TADIÉ, Marc. Le sens de la mémoire. Paris: Gallimard, 1999.

TODOROV, T. Mikhail Bakhtine. Le principe dialogique. Suivi de Écrits du Cercle de Bakhtine. Paris: Éditions du Seuil, 1981.

VOLÓCHINOV, V. Marxismo e filosofia da linguagem: problemas fundamentais do método sociológico na ciência da linguagem. Trad., notas e glossário de Sheila Grillo e Ekaterina Vólkova Aérico; ensaio introdutório de Sheila Grillo. São Paulo: Editora 34, 2017.

Recebido em 25/05/2018

Aceito em 16/07/2018. 